\title{
Article
}

\section{Science on the net: an analysis of the websites of the European public research institutions}

\author{
Laura Massoli
}

This article introduces a study on the websites of several European public research institutions aiming at identifying the science communication model chosen and implemented online with the purpose of reaching different target publics. The analytical approach takes into account a number of indicators: from the institutional identity to the scientific features, from the interactive services to the internationalisation level, in order to evaluate whether the web provides an added value in the adopted communication model and in building a relation with the users. Lights and shades emerge from this study in which good practices side examples of a much weaker science communication approach, outlining a general context where a public research institution website has been still used as a presentation tool and its interactive opportunities have not been capitalised.

\section{Introduction}

A major technological development has considerably boosted the use of the web as a communication tool. Even in the specific field of the public science communication, the web is ever more frequently seen as an opportunity to provide information and to spur participation on scientific-institutional issues about which, as revealed also by the recent Eurobarometer $2005,{ }^{1}$ the public feel they still lack information and require involvement.

The transparency of the scientific information on the internet and the creation of a relation with one's users are therefore needs that major public scientific institutions are facing in a pressing way, searching for a communication model that combines scientific rigour with the use of interaction and communication tools and institutional credibility with the need to address a complex and stratified public. The analysis of the web communication positioning of those institutions is useful to understand whether the chosen model is either simply a "transmissive and informational one" or one more based on relation-building. Indeed, whereas the use of new technology can guarantee a further opportunity to develop a scientific culture, this opportunity implies a series of choices and organisational innovations to be pursued first and foremost within the administration (in this case the scientific one).

Firstly, it implies a new institutional approach, neither to be downplayed nor confined to self-reference, but rather to be an effort to present and offer information, services, useful opportunities, set on the needs and the profiles of the reference publics.

\section{An analysis of the websites of the European research institutions: general goals and methodology of the research}

In the context described above, the research carried out has involved 66 websites of European public research institutions, with a dual research goal:

- on the one hand, to analyse the communication model chosen by the institutions involved and implemented through their websites;

- on the other hand, to define whether, in the science communication path adopted, the use of the web as a communication tool, is either a real value added - given the multi-media, interactive and

\footnotetext{
${ }^{1}$ Commission of the European Communities, Special Eurobarometer 224: Europeans, Science and Technology, June 2005. Online version: http://ec.europa.eu/public_opinion/archives/ebs/ebs_224_report_en.pdf.
} 
relational and immediacy potential it offers - or it simply is the "networking of information that could be accessible also through other media".[17]

The research was structured on the basis of a surveying grid that includes a series of indicators (68) divided into 6 field areas, representing aspects of "public communication", public service and scientific characterisation:

1. Institutional identity;

2. Relation-building with users;

3. Scientific credibility;

4. Services and interactivity degree;

5. Partnership and internationalisation;

6. User-friendliness and Accessibility ${ }^{2}$.

The websites involved in the survey are the following:

- Austria: Institute of Technology Assessment - ITA (www.oeaw.ac.at/ita/welcome.htm ) and Institute of Molecular Biotechnology - IMBA (www.imba.oeaw.ac.at/);

- Belgium: IMEC (www.imec.be/wwwinter/Welcome.html) and Belgian Nuclear Research Centre SCKCEN (www.sckcen.be/sckcen_en);

- Bulgaria: Bulgaria Academy of Science - BAS (www.bas.bg) and Central Laboratory of Solar Energy and New Energy Sources - SENES (www.senes.bas.bg/home_eng.htm);

- Cyprus: Agricultural Research Institute - ARI (www.ari.gov.cy) and Cyprus Research and Educational Foundation (http://www.cyprusinstitute.ac.cy);

- Croatia: Ruder Boskovic Institute- IRB (www.irb.hr/en) and Institute of Physics (www.ifs.hr/en);

- Denmark: Risoe National Laboratory (www.risoe.dk) and Danish National Environmental Research Institute - NERI (www.dmu.dk/International);

- Estonia: National Institute of Chemical Research (www.kbfi.ee/?id=56\&lang=eng) and Estonian Biocentre - EBC (www.ebc.ee/EBC);

- Finland: Finnish Environment Institute - SKYE (www.ymparisto.fi/default.asp?node=5297\&lan=en) and Agrifood Research Finland MTT (www.mtt.fi/english);

- France: National Center for Scientific Research - CNRS (www.cnrs.fr/index.html) and French Atomic Energy Commission - CEA (www.cea.fr/gb/index.asp);

- Germany: Fraunhofer-Gesellschaft (www.fraunhofer.de/fhg/EN/index.jsp) and Max Planck Society - MPG (www.mpg.de/english/portal/index.html);

- Greece: National Centre of Scientific Research DEMOKRITOS (www.demokritos.gr/istoriko_uk.asp) and Foundation for Research and Technology Hellas - FORTH (www.forth.gr/about-forth.html);

- Ireland: Science Foundation Ireland (www.sfi.ie) - SFI and Marine Institute (www.marine.ie) RIA;

- Iceland: Marine Research Institute - MRI (www.hafro.is/index_eng.php) and Nordic Volcanological Center (www2.norvol.hi.is);

- Italy: $\quad$ Consiglio Nazionale delle Ricerche- CNR (www.cnr.it) and Ente per le Nuove Tecnologie, l'Energia e l'Ambiente - ENEA (www.enea.it);

- Latvia: Latvian Institute of Organic Synthesis - OSI (www.osi.lv) and Institute of Physical Energetics - FEI (www.innovation.lv/fei);

\footnotetext{
${ }^{2}$ Methodological note: the grid was implemented, through a direct survey, on 66 websites of European public research institutions. The countries involved in the survey, consistently with the Eurobarometer approach, comprise the 27 EU member countries, the EU candidate countries (Croatia and Turkey) and the three EFTA countries (Iceland, Norway and Switzerland). Furthermore, the US was added. For each of the total 33 countries involved, two websites of research institutions were chosen on the basis of the following criteria of scientific and institutional homogeneity:

- websites of public research institutions with an English version;

- (if applicable) multidisciplinary research institutions that, aside from aspects related to the basic research, offer also an applied research approach and of technological transfer to the industrial world;

- the preferred subjects, whenever it was not possible to identify multidisciplinary science institutions, were the following: energy, environment, physics, technology and earth science.

The survey was carried out over the period from 28th August to 15th September 2006, and therefore does not take into account any change subsequent to that period.
} 
- Lithuania: Institute of Biotechnology - IBT (www.ibt.lt) and Institute of Lithuanian Scientific Society (http://msi.lms.lt/about_en.html);

- Luxemburg: Resource Centre for Environmental Technologies - CRTE (www.crte.lu) and Centre de Recherche Public - Gabriel Lippmann -CRPGL (www.crpgl.lu);

- Malta: Malta Council for Science and Technology (www.mcst.org.mt) and Malta Environment \& Planning Authority - MEPA (www.mepa.org.mt);

- Norway: Norwegian Institute for Agricultural and Environmental Research - Bioforsk (www.bioforsk.no) and Research Council of Norway - RCN (www.forskningsradet.no);

- Netherlands: Energy research Centre of the Netherlands - ECN (www.ecn.nl/en) and Netherlands Institute of Ecology - NIOO-KNAW (www.nioo.knaw.nl/indexENG.htm);

- Poland: Polish National Energy Conservation Agency - KAPE (www.kape.gov.pl/EN/index.phtml) and Institute of Plant Protection (www.ior.poznan.pl/English/Anglik.htm);

- Portugal: Institute for Molecular and Cell Biology - IBMC (www.ibmc.up.pt) and Centre of Marine and Environmental Research - CIMAR (www.cimar.org);

- United Kingdom: Natural Environment Research Council - NERC (www.nerc.ac.uk) and National Measurement Laboratory - NPL (www.npl.co.uk);

- Czech Republic: Czech Energy Agency - CEA (www.ceacr.cz/?page=titulni_en) and Academy of Sciences of the Czech Republic - ASCR (www.cas.cz/index.html.en);

- Slovak Republic: Slovak Energy Agency - SEA (www.sea.gov.sk/english/index.htm) and Slovak Academy of Sciences (www.sav.sk/?lang=en);

- Romania: National Institute of Research and Development for Earth Physics - NIEP (www.infp.ro) and National Institute for Research and Development in Microtechnologies - IMT (www.imt.ro);

- Slovenia: National Institute of Chemistry Slovenia - NIC (www.ki.si/index.php?id=117\&no_cache=1\&L=1) and National Institute of Biology NIB(www.nib.si/en);

- Spain: $\quad$ Research Centre for Energy, Environment and Technology - CIEMAT (www.ciemat.es/portal.do) and Council for the Extension of Studies and Scientific Research - CSIC (www.csic.es/quien_somos.do);

- Sweden: Swedish National Testing and Research Institute - SP (www.sp.se/en/Sidor/default.aspx) and Swedish Research Council (www.vr.se);

- Switzerland: Swiss National Supercomputing Centre - SNSC (www.cscs.ch) and Paul Scherrer Institute - PSI (www.psi.ch/index_e.shtml);

- Turkey: The Scientific and Technological Research Council of Turkey - Tubitak (www.tubitak.gov.tr) and Marmara Research Center (www.mam.gov.tr/eng);

- Hungary: Chemical Research Center - CHEMRES (www.chemres.hu) and Institute for Matrilas Science and Technology - Bayati (www.bayati.hu/en_linkek.html);

- United States: National Renewable Energy Laboratory - NREL (www.nrel.gov) and Fermi National Accelerator Laboratory (www.fnal.gov).

\section{Results of the analysis}

\subsection{Presentation of the institutional identity}

The concept of institutional identity refers to a set of visual and non-visual messages used to represent or to symbolise an institution allowing the public to recognise it. In this perspective, identity is not seen as something immutable and "ultimate", but as a dynamic element that develops along with the organisation itself and the external changes which, in a continuous process, happen to modify also the institution's attitudes and behaviours. In the case of the administrations involved in this research, the identity aspect is a crossroad between the public elements and the scientific ones. 


\begin{tabular}{|l|c|}
\hline LABEL & \\
\hline about/institution name/mission/role/chart & 67 \\
\hline research/science/activities/research line name & 26 \\
\hline services/facilities & 22 \\
\hline news & 20 \\
\hline departments/centres/institutes & 15 \\
\hline Contact/info/link/search/home & 13 \\
\hline education/funding/awards & 12 \\
\hline partners/projects & 9 \\
\hline people/personnel & 9 \\
\hline Publication & 3 \\
\hline public interest & 2 \\
\hline
\end{tabular}

Table 1 First three items on the content menu (absolute value).

In particular, in the web identity analysis, some significant data were drawn on the homepages of the websites, seen as initial and introductory "business cards" to the navigation, the interaction and also to a simple search of information. In this regard, the websites show a good institutional recognisability, thanks to a widespread presence of a logo in their homepages (59 websites out of 66 ), the institution name's visibility ( 65 out of 66 ) and the easy connection between the name of the institution and the website URL (55 websites out of 66).

An important aspects in the "institutional identity" indicator was also examined by surveying the semantic labels of the first three items on the homepage content menu of each website, that is usually displayed on the left of the homepage. The construction of logical aggregations allows for a possible interpretation to the implemented communication strategies, as presented below. ${ }^{3}$

As table 1 reveals, the main communication approach is oriented towards the presentation of institutional features, related to the institution as a public administration with its own role, mission, structure and history (67 occurrences for the label about and related topics). The research issues, which correspond to the institution's core business, follow (26 occurrences for the label research and related topics), then the services and the facilities provided externally (22 occurrences for the label services and related topics) and finally the news (20 occurrences).

This element emerges even more clearly by analysing the position of each of the three labels with the highest number of occurrences (about - research - services - c.f. table 1) within the first three content items in each website: as figure 1 shows: about is the most used label as a first item on the content menu (48 occurrences), research is the most used one as a second item on the content menu (15 occurrences) and finally services is the most frequent one as a third item (10 occurrences), allowing to define, aside from a semantically-relevant list, a presentation order (indeed, about, research, services in this sequence), which seems to be quite recurrent and typical for the websites analysed.

\subsection{Engaging the public: roles and scope of science communicators}

A central point in the analysis of the public research institutions' websites regards whether and how they are able to establish a communicative relation with their users. These institutions - aside from specific and niche targets (other researchers and specialists) - address the general public, schools, enterprises and media, hence this relation is also to be analysed at different levels. As regards the strategies devised to address the general public and the media system, the institutions involved have proved still not too

\footnotetext{
${ }^{3}$ The"semantic label" analysis in the home page has been structured in different phases: a) analysis, for each website, of the first three items on the content menu. The total 198 labels gathered were further grouped into similar semantic areas (for example, the labels about/mission/role were all grouped in the same semantic area, and research/science/activities in another one). b) occurrences count in absolute value, for each group identified (as shown by table 1, whose total is 198 indeed). c) occurrences count, for each group, according to the position of the label in the content menu (first, second or third item): this analysis allows to define the order of presentation and importance of the items - and therefore of the contents - in the websites involved (as shown in figure 1).
} 


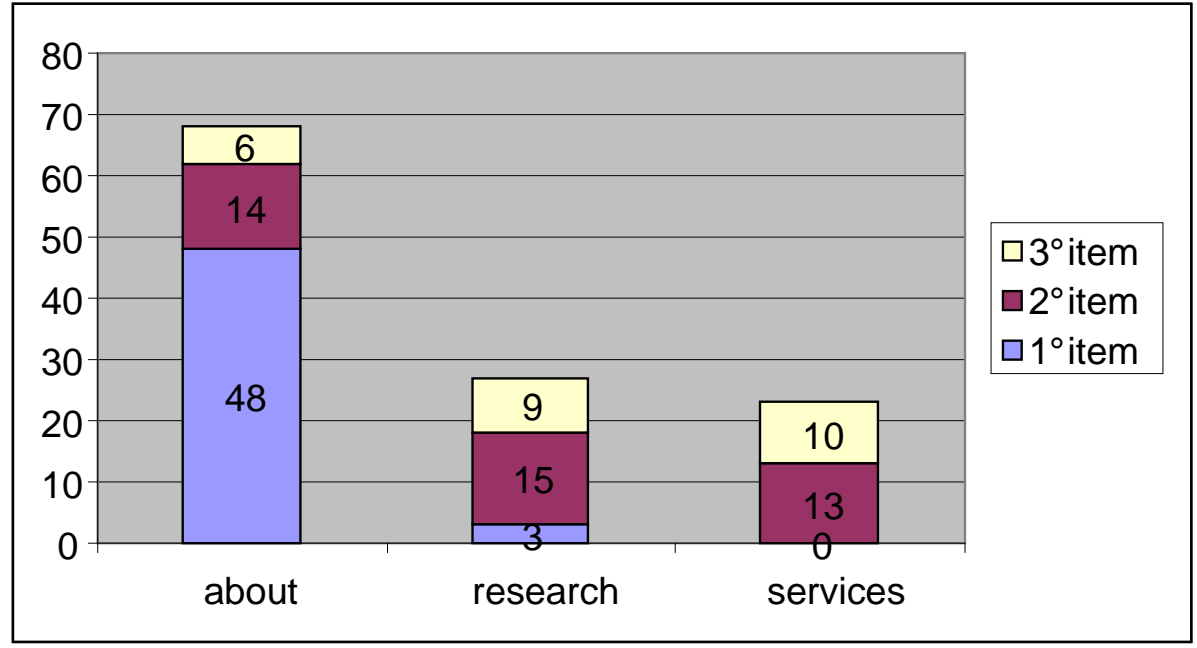

Figure 1. Labels in the content menu by position (absolute value).

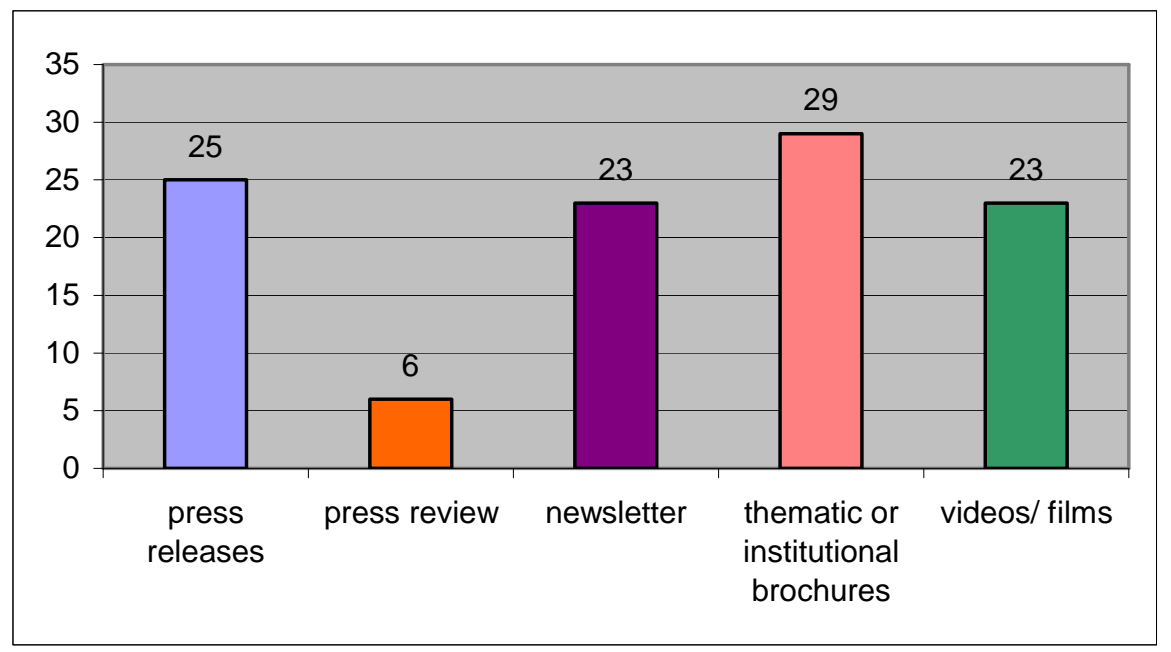

Figure 2. Communication products available online (absolute value).

careful in presenting online the communication/information/press offices.. Only $20 \%$ of the websites (13 out of 66) has a section, more or less wide and accurate, featuring the press office and only $23 \%$ (15 websites out of 66) have an online area for a communication/public relations department. However, there are also various best practices: the Danish site of RISOE has a page featuring a communication policy, the British NERC website has even an entire section dedicated to the communication guidance aimed at raising a better awareness and at structuring, within the scientific context, the relation with the general public and the Austrian IMBA website has a section named experience IMBA with online resources related to science communication.

Whereas the science communication specialists are often "hidden", what stands out is their output, i.e. their actual communication tools and initiatives: press releases, films, thematic or institutional brochures (figure 2). A notable example is the one provided by press releases: even though there is no reference to the press office or press officers, press releases are published and often featured in the homepages. Hence, at this stage, the relevance of this new profession, i.e. the science communicator, is shown and proved by the results and the output of its activity.

On the other hand, analysing the interaction tools available to the users to contact the institutions, what emerges is that the prevailing ones are very basic, i.e. a generic e-mail address, followed by far by a form 


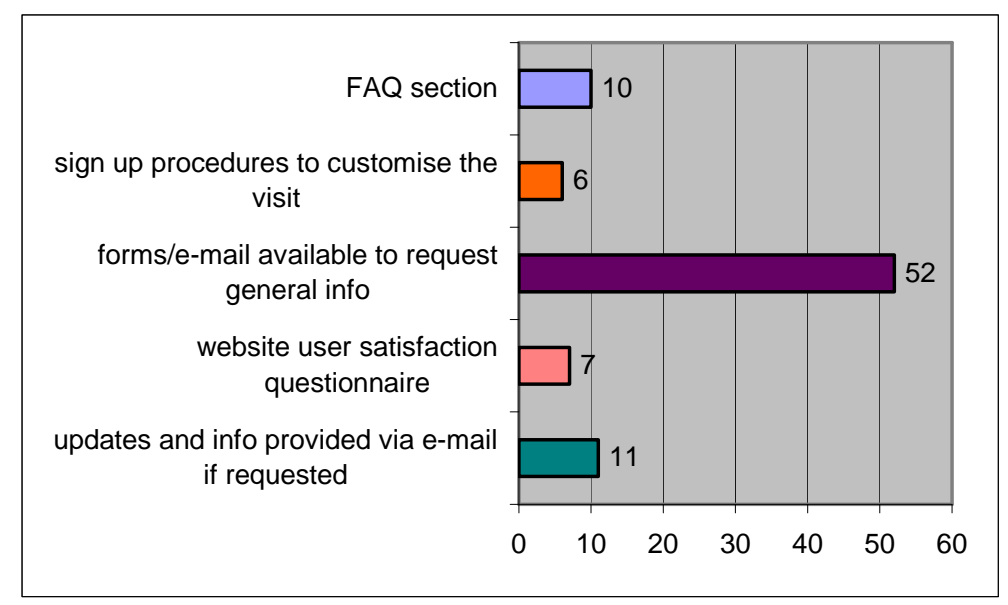

Figure 3. Relation building: instruments available to the users (absolute value).

to submit your own e-mail address to receive information, news, events or the presence of FAQs - being the latter a very useful option and easily to be technically implemented, yet rarely used (featured in 20 websites only). Even rarer are the satisfaction questionnaires and the procedures to sign up and customise the visit, accessible on 6 websites only (figure 3).

Two interesting examples of user registration to build a user "fidelization" in visiting the websites are provided respectively by the Belgian IMEC and by the Norwegian Research Council. The former offers a my IMEC space where users can build their own site by choosing customised information contents; the latter provides a $M y R C N W e b$ that requires the users to sign up to receive a newsletter, to apply for grants and other contests or to receive specific and detailed information on projects and reports by the institution. The user fidelization concept, whose origins draw on the internet marketing, is developing also in institutional and specialist fields (such as the research institutions' context). It demonstrates that also in such a context awareness is raising on the need to engage the users, offering specific and ondemand information aiming at a better and better communication quality.

\subsection{The scientific dimension}

The scientific dimension certainly is the most peculiar and strategic aspect within this analysis, since it helps to understand how the scientific category is communicated and presented on the web. In the analysis of this dimension, three aspects have been particularly taken into account: authoritativeness, transparency and credibility.

\subsubsection{Authoritativeness}

The concept of authoritativeness concerns the set of skills and professionalism that an institution (in this case, a research institution) possesses and demonstrates. ${ }^{4}$ In particular, they can be drawn on indicators such as:

- in-depth information and command demonstrated as regards institutions' lines of research, through updated and well-structured information on its themes;

- specific data on the institutions' scientific productivity (for example, the number of publications, type of journals, congresses organised, number of patents, etc.)

On the basis of these indicators, the institutions possess a good know-how when presenting the most general contents (fields of the activity of the institution, list with detailed information on their lines of

\footnotetext{
${ }^{4}$ For the definition of authoritativeness cf. the study on the Web Credibility by the group of the Stanford University, available online on www.webcredibility.org
} 


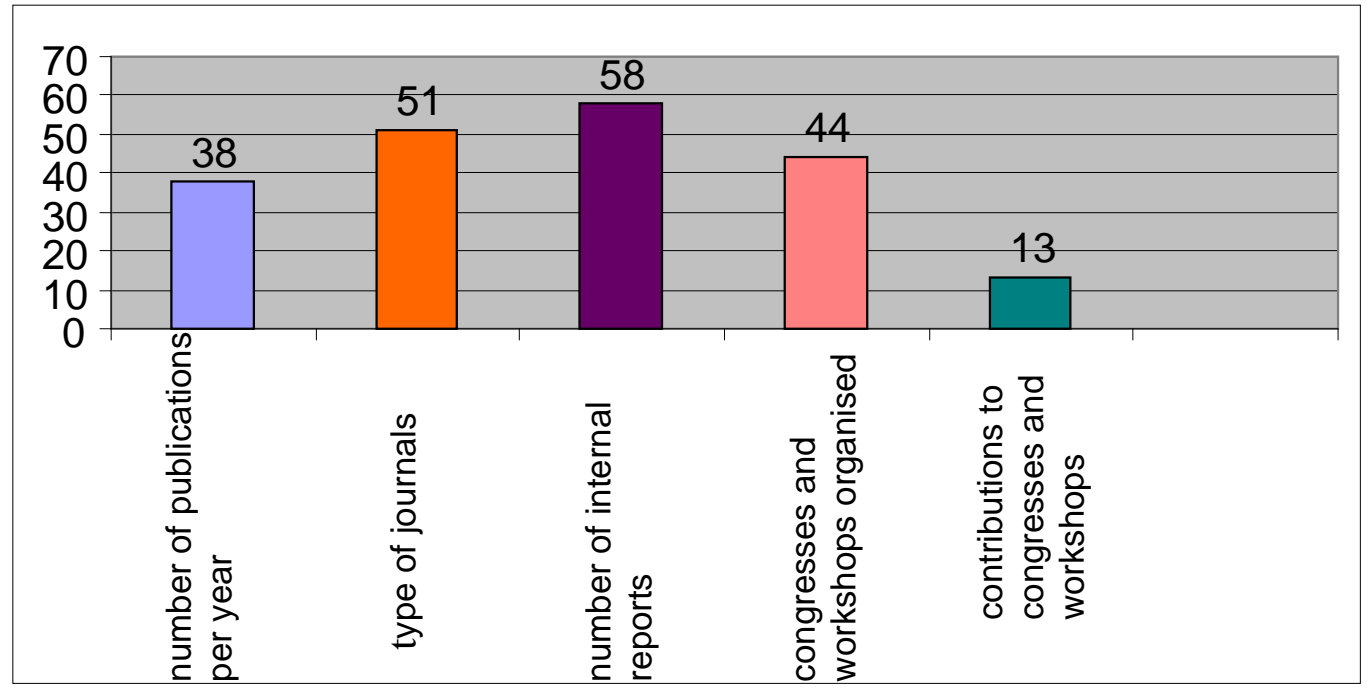

Figure 4. Presence of online data on scientific productivity (absolute value).

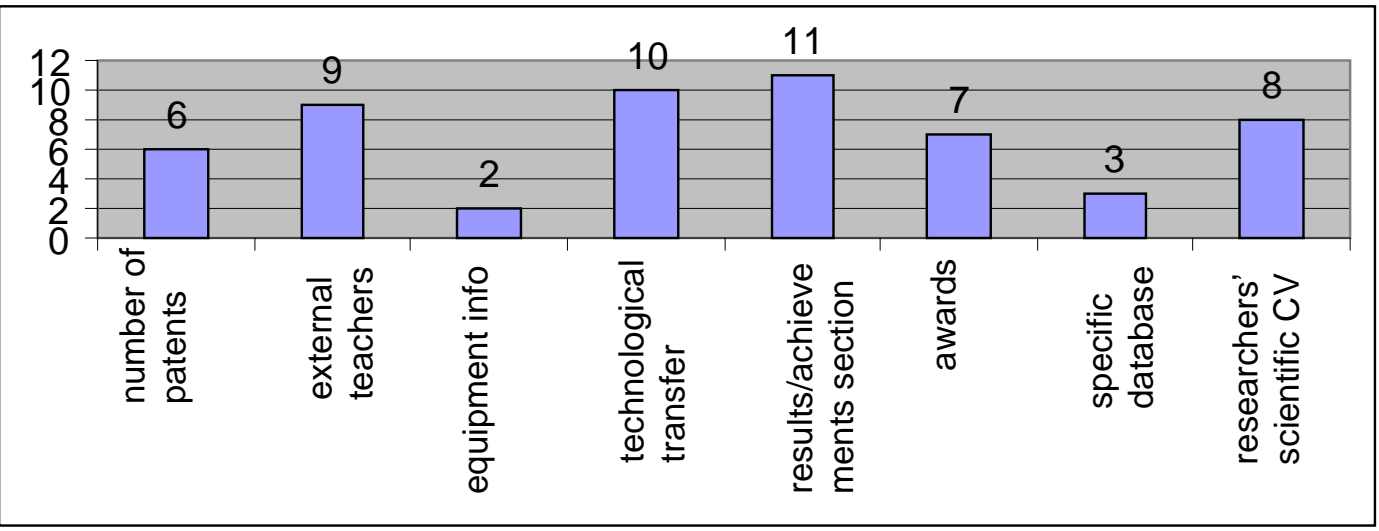

Figure 5. Other online data on scientific productivity (absolute value).

research), but the issue is more complicated as regards the information on the scientific productivity that needs very specific and standard data. In this case, aside from some well-publicised traditional data (number of internal reports, number of publications per year, type of journals, congresses organised, as shown in figure 4) there are some others (shown in figure 5), more related to aspects of the technological transfers and therefore to the more applicative results of research (e.g. patents), whose publicity is still quite limited. The result is a traditional communicative positioning, in which the typical features of the scientific peer group relation-building are prevailing on others related to different and emerging targets (the industrial world of patents and the university teaching context, only to mention a few).

One last aspect to be mentioned in the analysis of the scientific authoritativeness regards the existence of a concordance between the importance attached to the aspects of the public engagement with science (analysed in $\S 3.2$ ) and the one related to the elements of science communication. The institutions that give a greater visibility to communication products for the general public (press releases, videos, brochures) are also those that, still in quantitative terms, present a wider and less conventional range of indicators of scientific productivity. This is the case of the Portuguese CIMAR that, in a large section of its website, features information and opportunities related to the technological transfer, or the Belgian SCKCEN website that devotes part of its pages to the research results, illustrating its collaborations with the industrial world. 


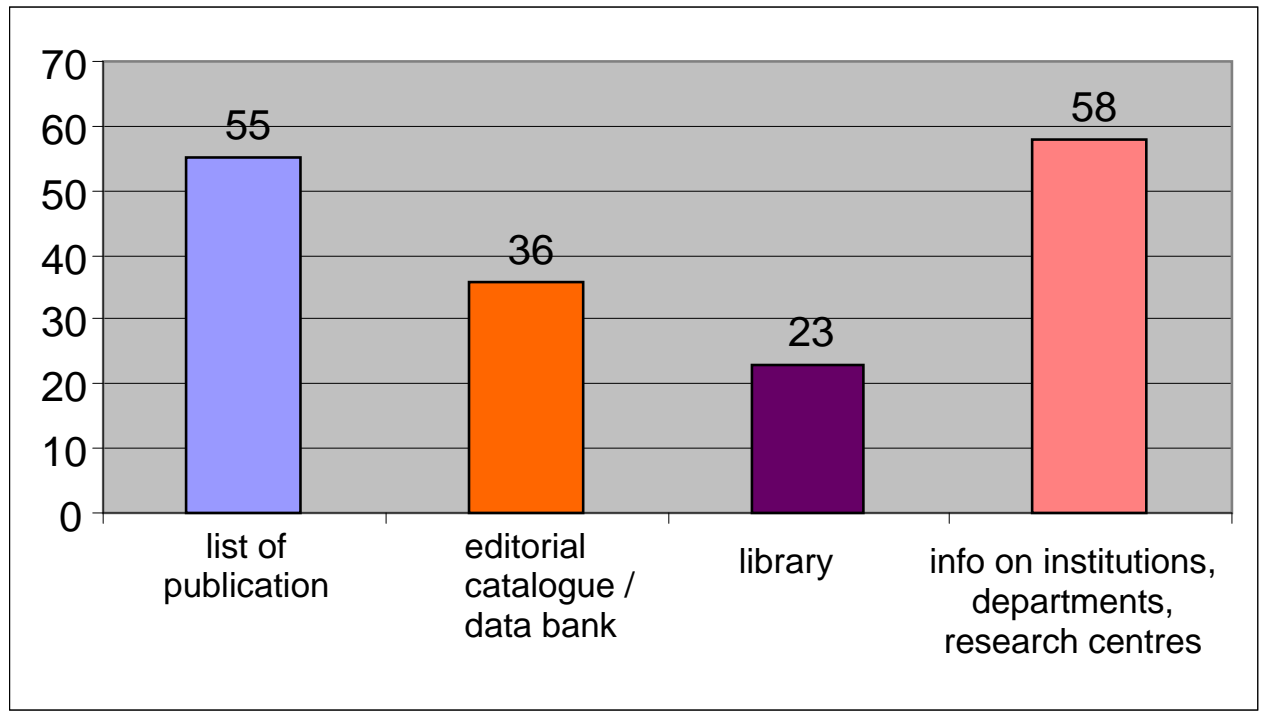

Figure 6. Presence of scientific information (absolute value).

\subsubsection{Scientific transparency}

The concept of scientific transparency refers to the "expertise of the research institution in presenting in a clear form the features and the results of its activity".[17] The web tools break the tradition of "not publicising information", widening considerably the access opportunities and suggesting a new way of communicating and disseminating the research, beyond time and space limits.

In respect to the mission, stated by all the institutions involved, and the presentation of information on their administrative structure (62 websites out of 66 provide information on the institution organization chart and the set-up of their administration), the institutions show an excellent awareness on the importance of the transparency on the contents related to the scientific research world.

The relevance of the "scientific transparency" in the communication strategies by the institutions involved is further stressed by the fact that the various portals quote the legal framework that, in each country, regulates the right to information and its access. For example, the British NERC website contains a section named Ethics and transparency, directly linkable from the homepage and the two Irish websites (Marine and SFI) have both some pages devoted to the FOI - Freedom Of Information Act, entered into force in Ireland in 1997, a norm that substantially corresponds to the Italian law no. 241/90 (and subsequent amendments, including the recent 15/2005). ${ }^{5}$ Similarly, the Maltese MEPA website includes a reference to the Freedom of Access to Information on the Environment Regulations, dated 2005, which establishes the right, for the community, to require and receive information on the environmental aspects from governmental institutions.

Furthermore, the institutions show good expertise and a widespread awareness in presenting information on their departments and research centres (58 websites out of 66), on their library (23 websites out of 66), on their editorial catalogue (36 websites) and also in providing a list of the internally-produced publications (55 websites; figure 6).

Focussing on the quality of the information available, once again the final scenario is positive: not only a list of the publications is usually featured (55 websites, $83 \%$ ), but in $39 \%$ of the cases is also possible to read and download the whole article, $6 \%$ of the sites provide an abstract to the article and $38 \%$ mention at least the main references needed to find it; not only there is an editorial catalogue ( 36 websites, $54 \%$ ), but in $42 \%$ of the cases it provides some specific search tools; and finally, when a library is available online (23 cases, $35 \%$ ), in the majority of the cases (19 websites) it provides a section with information and digital services. These data demonstrate that, the institution, in putting some scientific content online, has done an aware choice of quality and added value, not simply by trying to provide information in a further format, but to favour and widen its access, exploiting the interactive potential of the internet medium.

\footnotetext{
${ }^{5}$ It is the law "Amendments to law no. 241 of $7^{\text {th }}$ August 1990, on the general rules for the administrative action".
} 
Another important aspect related to the scientific transparency regards the profiling of the contents, with the purpose of "going beyond the self-reference in communication, in the attempt to organise the contents according to the informative needs of the potential users". ${ }^{6}$ In particular, the profiling analysis is useful to assess whether a structured science dissemination and communication model exists within the website. This approach implies, beside the traditional structuring of the contents by themes or departments (as is the case of the public administration, such as those considered), the one by user type, so as to guarantee more opportunities of accessing the same contents. However, the data show quite a lacking situation: only 8 websites out of 66 adopt a content profiling system by user groups. The user categories include: students (Portugal CIMAR, Belgium IMEC, Croatia IFS), the press (Italy ENEA), researchers (Germany Max Planck, US Fermilab) and children (Norway Forsk).

\subsubsection{Scientific credibility}

The web credibility concept is drawn from some research projects carried out by the Stanford University: highly credible web sites will be perceived to have high levels of both trustworthiness and expertise [15].

The first element that involves credibility is a clear explanation of the websites' purpose. The research institutions involved in the analysis aim at achieving three main goals: to promote their institutional image (58 cases, $88 \%$ of the websites), to present their lines of research (52 cases, $79 \%$ of the websites) and their internal staff structure (30 cases, $46 \%$ of the websites). This data is consistent with what has been said about semantic labels (cf. § 3.1), thus outlining a scenario in which the web is mostly used for institutional communication and to present scientific activities, nearly as an "online brochure". Therefore, what emerges is a strong institutionalisation of the online public science communication, to the detriment of other utility aspects, only partially available online, such as the services offer and the training opportunities.

Another aspect related to scientific credibility concerns the update of the information provided by the website. This is not a specific procedure of the research institutions' websites, but in this case it acquires a special relevance as, by definition, scientific information acquires its rigour and value on its "freshness".

Technically speaking, adding the date of the last update is not a complex procedure, yet it reflects a journalistic approach in managing the content within the editorial office of the website. Only very few websites invest on this aspect: only $15 \%$ of them mention (at least on the homepage) a date for the last update within the past month, whereas $65 \%$ of them do not provide any information at all and $20 \%$ display a date which is older than a month. An interesting model, within the analysed websites, is offered by the Croatian IRB that provides a system that highlights, in a box on the right of the homepage, the last content added, updated and changed, facilitating the user's visit and search for news.

\subsubsection{The scientific advisors}

The need to provide information about contact persons is particularly important in the case of research institutions' portals, both to provide accountability on scientific issues and to guarantee a direct contact on projects, publications and research reports. From a merely quantitative point of view, 60 websites out of 66 provide some contact with their scientific advisors. Analysing specifically the tools available, the email is now the prevailing tool, but it is still followed by the telephone, the mail address and the fax (figure 7). It emerges a "positive redundancy", so that in 52 cases (out of the 60 websites that offer any contact), the users have three or four different methods to contact the advisors, according to a multichannel access system that, on the basis of technology, does not tend to cut the interaction tools, but rather to join them synergically.

\footnotetext{
${ }^{6}$ By the expression "content profiling of a website by user groups" it is meant the website's content organisation according to specific target segments. This model was initially adopted by the portals of the local municipalities, next to traditional approach of presenting the services and the administration structure. For example, see the institutional portal of New York City - www.nyc.gov - which was among the first to choose this approach, by identifying the items (profiles - semantic levels) of Residents, Business, Visitors and Government. In a website, a content profiling model allows for a facilitated access and an easy web navigation. This research was aimed at verifying whether this approach could be applied also to the portals of research institutions that, as demonstrated, have different target groups such as students, researchers and the likes.
} 


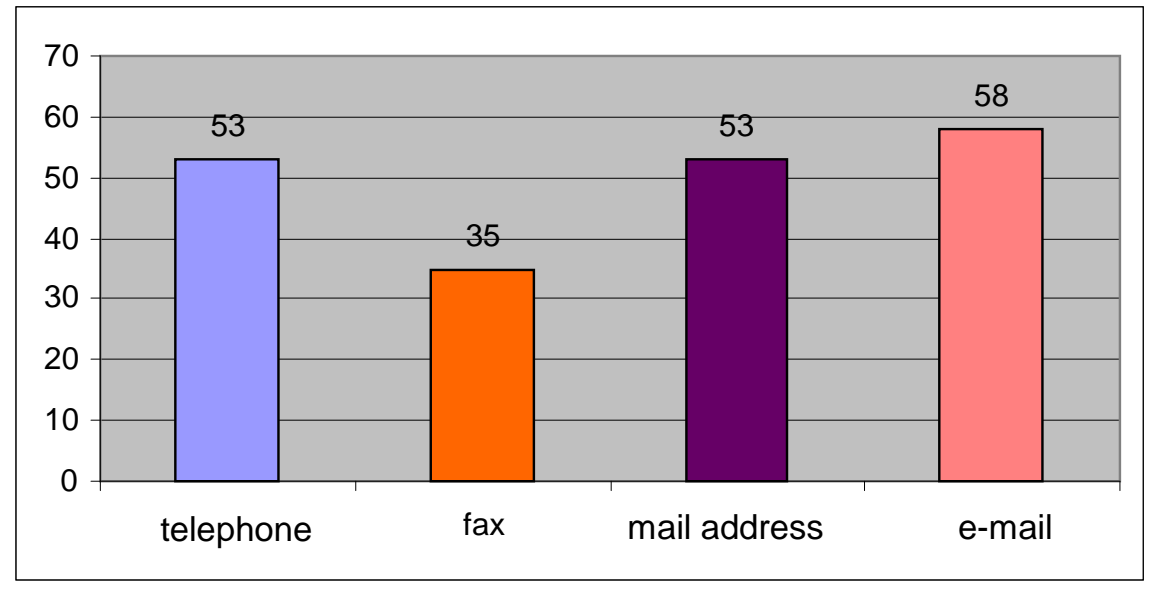

Figure 7. Methods to contact the scientific advisors (absolute value).

A further evolution, in this case, is the presence of interaction forms on science-related issues (that include communities among researchers, but also debates on the net), with a view to implement, also thanks to the technological potential, a closer and more functional relation with their publics. Counting all the forums on scientific issues, public consultations, ask-a-scientist services, communities, tutorials for education and collaboration on the net, tell-a-friend and forms to suggest events to be published, there is a very limited total of 27 examples of interactive tools that, also owing to their small number, can nearly in all cases - be models for best practices.

Among them, some particularly significant solutions come from the Maltese MEPA that, aside from providing a forum on energy savings, has a public consultation section and provides news and updates via texts directly on one's mobile phone. The Irish Marine website provides information about the weather and temperatures via texts, has a technical forum and provides a form to request data from the archives; the British NERC website has some forums and a space devoted to public debates with scientists, policy makers and NGOs. These examples appear extremely interesting for the interactive and socialisation potential they offer and also because they demonstrate that it is possible to use the internet for innovative and engaging communication models.

\subsection{Services to the users}

The analysis on the services provided by the European research institutions' portals has been divided into strictly scientific services (grants, research fellowships, contracts and tenders) and information and science communication services.

This second field features the presence of news, event calendars for activity promotion, workshops, conferences, studies and research projects for quite a general public. With respect to news and events, they are available and listed in a visible way on the homepages, highlighting the effort made by the majority of these websites to shift towards a journalistic information approach (figure 8). For example, the Finnish MTT website offers, on its homepage, life stories, i.e. experiences of young researchers belonging to its own institute, describing not only their research activities, but also their personal approach to the scientific career, in order to move, by illustrating some cases, the figure of the researcher closer to the public, promoting the image of science and of a scientist not only in project and activityrelated terms, but also as a life experience.

Referring to the analysis of the scientific services, the situation seems to be less positive:the majority of the websites do not provide much information (figure 9), except for research fellowships/doctorates, training courses/workshops and the selection procedures/contests - the only services about which at least half of the institutions provide some information. 


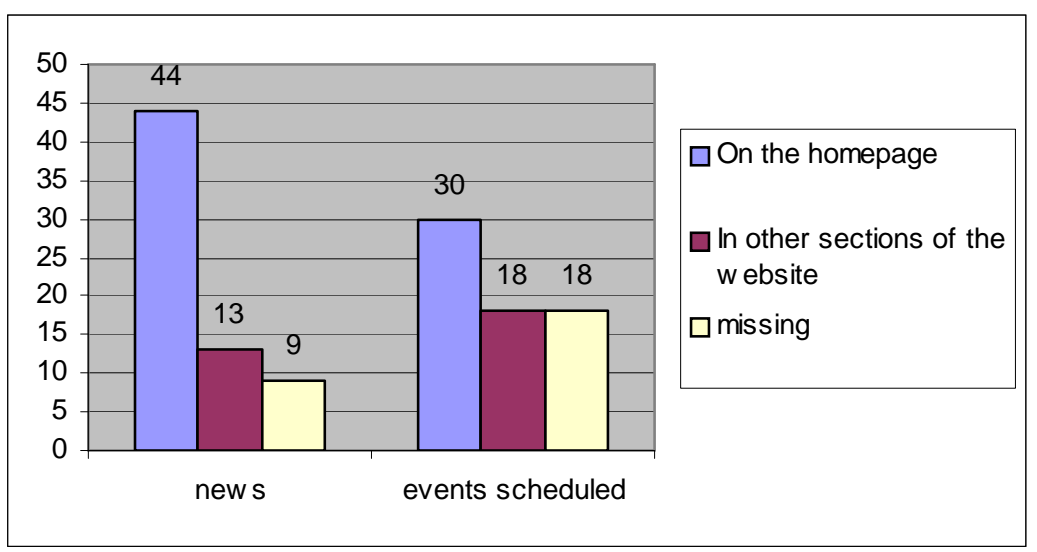

Figure 8. Scientific information services: news and events (absolute value).

Aside from the mere quantitative data about the actual service presence/absence, the analysis has also considered the interactivity dimension, in order to assess the effective service quality level and the relation with the user. ${ }^{7}$ In the case of some services, such as the training courses, the competition procedures, the doctorates/research fellowships, the highest figures (respectively 18, 11 and 11) regard an high level of interaction (level 3: general information and e-mail provided for contacts) showing that the use of the net and of the website could play a functional role in pursuing a better effectiveness, transparency and administrative efficiency.

This positive aspect, though counterbalanced by the small number of administrations which actually provide scientific services, points to a growing trend in the quality level of services' management and supply, towards a more relational model.

\subsection{The research network}

The aspects related to the creation of a "research partnership", by networking similar and converging information, are particularly significant within an analysis of the online communicative approach by the scientific institutions. Since the internet has born precisely as a virtual sharing and exchange network among researchers and research institutions, the implementation of international networks is apparently one of those organisational and communicative models the use of the internet may provide a peculiar and significant contribution to, creating an added value and a substantial differentiation, compared to previous and nondigital frameworks.

The first indicator considered is the linguistic one, which may be an initial barrier to the creation of any kind of cooperation. Research institutions appear to be aware of the importance of a linguistic common denominator. Obviously, the selected language is English, and $42 \%$ of the websites involved, aside from the version of the site in the local language, have a complete English version; 32\%, aside from their local language, provide part of the site in English, 5\% implements, aside from the local language and English, a further third language (for example, the Belgian IMEC and the Luxembourgian CRTE websites have also a French version, whereas the Swiss Paul Scherrer has some sections in Chinese), $18 \%$ has decided to put online only the English version, without the local language (this applies particularly to the less common languages, such as Estonian, Greek-Cypriot, Latvian and Romanian). Only 3\% of the websites still have, as the only version, the one in the local language.

\footnotetext{
${ }^{7}$ In the European context, the eEurope 2002 programme identifies a services' interactivity scale on four degrees so that the higher the interactivity degree, the better the level of innovation of the service provided. That model was adopted for this analysis, though adapted to the special features of the services provided by the websites analysed, identifying four progressive steps: -general information available online;

-general information and form/e-mail for contact;

-general information, form/e-mail and downloadable forms;

-general information, form/e-mail and forms to be filled in and sent online.
} 


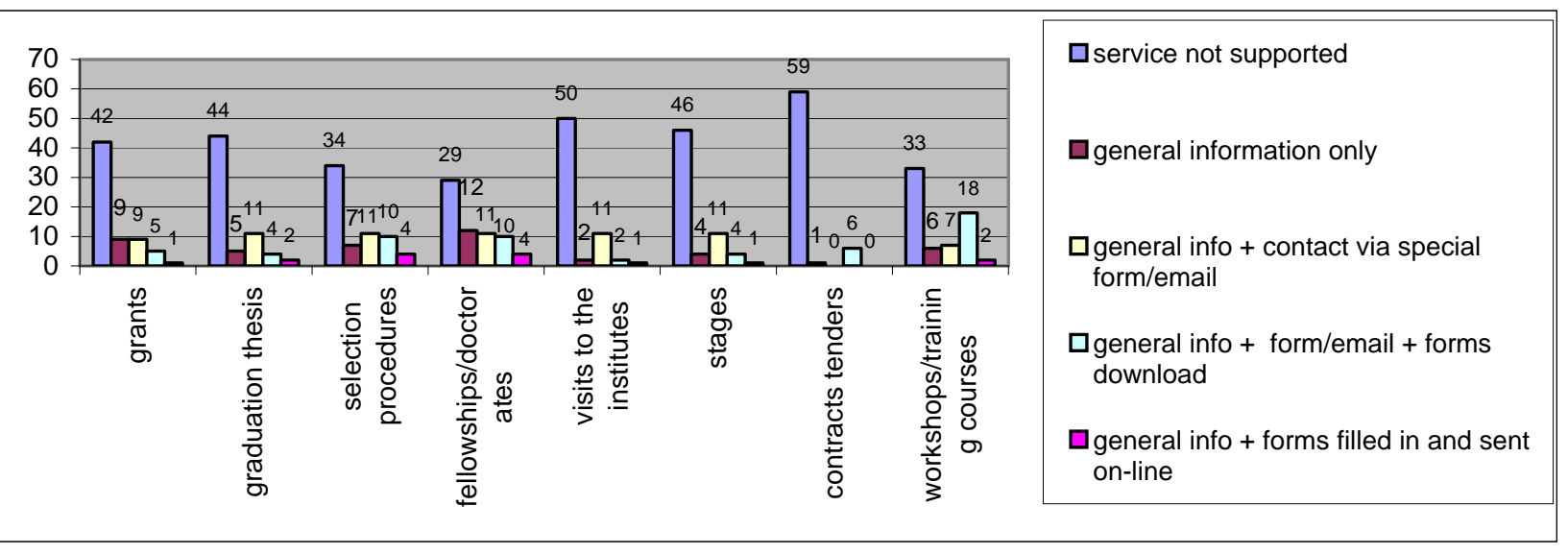

Figure 9. Scientific services and their interactivity degree (absolute value).

A second significant aspect of the scientific internationalisation regards the "website referentiality", i.e. the number of times a website has been mentioned in other portal and in other webpages. Hence, the "website referentiality" shows the website's visibility in the virtual space and, consequently, how many times it can be found surfing the net, also on websites dealing with similar topics. ${ }^{8}$

Two diverging models seem to coexist: on the one hand, $45 \%$ of the websites (30 cases) has over 10,000 references and 6 of them (among which the Italian CNR, the two German Fraunhofer and MPG and the Irish Marine) have more than 100,000, thus showing a significant positioning in the virtual survey of research; on the other hand, 31\% (21 websites) has less than 1,000 references and, among those, 7 websites (the Latvian FEI, the Irish NVC, the Bulgarian SENES, the Cypriot Cyprus Institute, the Austrian IMBA, the Polish KAPE, the Czech CEA) even have less than 100, which means that they are not even "mentioned" on the net.

\subsubsection{Partnership}

The internationalisation aspect is functional to the partnership level, since the web visibility and the highlighted cohesion level are the starting point for establishing synergies and online collaborations. Figure 10 shows the indicators considered for the partnership analysis: the existence of a section devoted to the links to other institutions/scientific organisations, the presence of a section named "collaboration with other research institutions" and the indication of the participation to international projects. The general rating is positive: 38 websites out of 66 do have a link section, ${ }^{9} 49$ websites have a space for the collaboration projects with other research institutions and 39 websites provide a link and access, from the pages of their websites, to scientific data banks managed by other institutions or in collaboration with them.

\footnotetext{
${ }^{8}$ In this research, the referentiality value has been calculated through the search engine Altavista (www.altavista.com): in order to know the number of external websites which have a link to (and consequently mention) the analysed website, it would be enough to type in the search field "link: name of the reference domain" (e.g. link: www.enea.it). This option confines the research only to the pages featuring the word "domain" in the host name of the web server and provides as a result the number of pages found and their addresses. The aspect of referentiality is to be considered as particularly strategic in the case of the websites of research institutions, that in any case belong to quite a definite context, in which the navigation proceeds by subsequent references, for example a thorough analysis of a specific activity or in the research of a publication or a specific author.

${ }^{9}$ As regards the linking system, some websites, e.g. the Finnish SKIE and the French CEA, instead of the typical separate section, provide those links in specific pages, connecting them to the contents, thus creating a cross linking that is more significant and precise from a semantic viewpoint.
} 


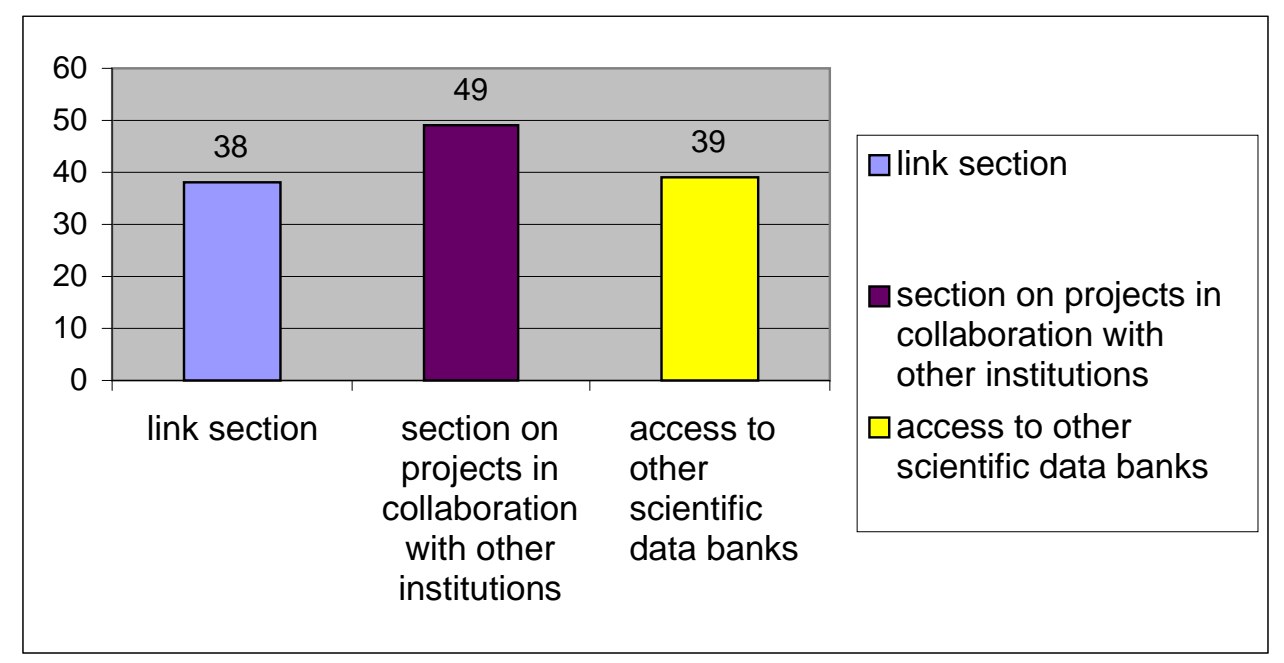

Figure 10. Partnership level with other institutions (absolute value).

\subsection{Usability and accessibility on the net}

The accessibility and the usability evaluation of the websites is a complex task as each country has implemented the EU eAccessibility and eInclusion directives and recommendation according to different rules and several technical levels ${ }^{10}$.

The reference model for a synthetic analysis approach, not meant to be excessively technical, although sufficiently comprehensive for the multi-faceted websites involved, has been a study - carried out in May and June 2005 by the UK Cabinet Office, during the British semester of the EU Presidency - aimed at measuring the accessibility of over 400 public websites in the 25 countries of the Union.

In particular, the study has been the source for some of the mentioned indicators: site map, breadcrumbs, alternative text to images/objects, pages with information about accessibility (figure 11). Some other indicators have been added (also shown in figure 11: search engine, recognisability of the links, existence of a link to the homepage on each page) which are more typically referred to the website usability aspects. The results highlighted in figure 11 show quite an evident divide: on the one hand, the usability indicators (search engine, link recognisability, and links to the homepage) achieve very high ratings while, on the other hand, the one related to accessibility result in considerably lower ratings: 29 cases for site map, 22 for breadcrumbs, 23 for text alternative to images and even 11 out of 66 for the presence of pages with information on accessibility.

Globally, the websites analysed are far behind in this process to "guarantee a larger access": only 2 websites out of 66 (4\%) have achieved an accessibility level higher than a single A, the Austrian ITA has reached a triple A (AAA) and the Dutch NERC a double A (AA), 18 websites (28\%) have achieved the minimum level of a single A (A) and the majority, 38 websites $(68 \%)$ have not achieved any level at all. ${ }^{11}$

\footnotetext{
${ }^{10}$ According to the ISO standard no. 9241 "Usability is the extent to which a product can be used by specified users to achieve specified goals with effectiveness, efficiency and satisfaction in a specified context of use", whereas accessibility is defined as "the ability of a computer system to provide services and information to all people, regardless of disability or severity of impairment, through assisted technologies" (Law 4/2004 "Provisions to favour the access of disabled people to computer instruments", also referred to as "Stanca law"). At international level, the initiatives to spread accessibility are coordinated by the World Wide Web Consortium - W3C, a body that deal with the identification of all the specifications which are the basis for the web, to favour an optimal development of the internet. In particular, the W3C has implemented since 1997 the Web Accessibility Initiative - WAI project, establishing workgroups on accessibility featuring all the major internet experts. Cf. www.w3c.org. At European level, a survey on the state of the activation and awareness-raising in each member state on those issues was provided by the British government during its last semester of EU presidency. UK Cabinet Office, eAccessibility of public sector services in the European Union, November 2005. Online version:

http://www.cabinetoffice.gov.uk/e-government/resources/eaccessibility/index.asp. Specific information are also available online: http://europa.eu.int/information_society/policy/accessibility/web/wai_2005/index_en.htm.

${ }_{11}$ The evaluation of the accessibility level was carried out through the automatic evaluator BOBBY-Webxact, available online free of charge at the following address: http://webxact2.watchfire.com.
} 


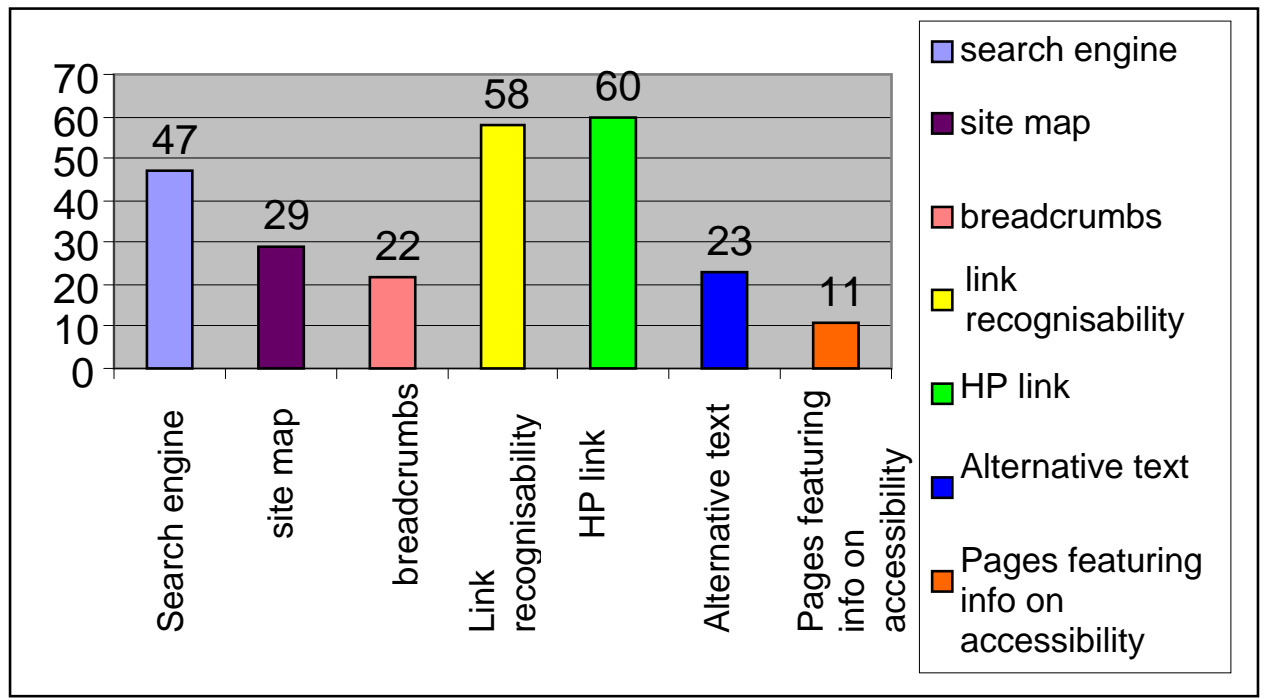

Figure 11. User-friendliness and accessibility (absolute value).

\section{Conclusions}

The analysis carried out offers quite a comprehensive survey on the web communication approach of the European public research institutions. Lights and shades emerge from this research, providing quite a controversial pictures, where examples of a major development are balanced by very weak points in the institution and communication profiles.

As regards the "added value" the web medium may provide, it can be noted that the European research institutions involved tend to use the internet mainly as a tool to convey scientific-institutional information. Thus, the "zero level" of the information access is apparently guaranteed. The user, surfing the web, is able to reach quite easily contents and news about a scientific institution, its projects and research activities, and may contact its advisors or read and download brochures and various documents.

Thus, the website provides the minimum required information, yet it appears nearly as a half-filled container.

The majority of the portals still are in their initial phase, where "the site is the display of the institution, as is - in other contexts - an institutional brochure".

Indeed, as regards the promotion of a scientific culture and the related forms of engagement, required and desired by the general public itself, the services and the possibilities provided by the websites have all been found lacking.

The interaction and participation opportunities are quite rare and the ones that have been detected are more devoted to specialists (forums and communities about "niche" scientific issues), rather than aimed at involving the general public.

A similar framework applies also to the online implementation of services for the different user groups: the research institutions still have some difficulties in offering a wide range of interactive scientific services (and not simply informational ones).

As a result, engagement and the offer of interactive services emerge as the weakest points and only some prominent scientific institutions, from advanced countries deeply involved in research and scientific communication (notably the US and the UK), have been promoting an initial investment and experimentation in these fields.

A further step should necessarily be taken in the process of the web public science communication in order to boost a more engaging model able to bring the scientific community nearer to the various targets.

In the end, a general analysis on the identified science communication model, may be proposed. The research highlights some excellence cases, specifically the portals of major scientific institutions (again from countries with a first-class scientific tradition - the British NERC and NPL, and the American 
NREL and Flab), which are able to join on the web the promotion of the institutional component with the supply of interactive services to their users. Aside from those best practices, the survey highlights some alternative (and quite interesting) approaches, provided by some "small-scale" institutions which implement some peculiar communication choices. Among these, the Greek FORTH site, which specifically invests on the "scientific credibility", showing a transparent approach and featuring much information on the scientific productivity of its researchers. Another scientific-communicative strategy emerges from the analysis of the websites of Romania IMT, Bulgaria BAS, Slovenia NIB and Slovenia NIC which rely on aspects of "partnership and internationalisation", to testify that, particularly for research institutions of "smaller" countries (such as those mentioned above) an opportunity for a qualitative and communicative development may lie in the promotion, enhanced by the web, of the research network, through synergies and cooperation with other similar institutions. This outlines a framework in which also "small-scale" scientific institutions, with limited resources, manage to stand out, implementing well balanced web communication strategies. These growth chances and scientific synergies offer innovative opportunities and best practices' examples for online science communication.

Translated by Massimo Caregnato

\section{References}

[1] M. Boscarol, Ecologia dei siti web, Hops Libri, Milano, 2003

[2] L.Cantoni et al., Comunicazione, Qualità, Usabilità, Apogeo, Milano, 2003

[3] Cap Gemini Ernst Young, Web-based Survey on Electronic Public services, Report for the European Commission - DG Società dell'Informazione, Brussels, 2002

[4] G. Carrada, Comunicare la scienza, Kit di sopravvivenza per i ricercatori, Sironi, Milano, 2005, online version: http://www.mestierediscrivere.com/pdf/comunicarelascienza.pdf

[5] Censis, Forum PA, Cittadini digitali, Roma, 2003, online version: www.censis.it

[6] Censis, Forum PA, Cittadini digitali, Roma, 2005, online version: www.censis.it

[7] Censis, RUR, E-Democracy - Un'opportunità per tutti, Roma, 2004, online version: www.censis.it

[8] Censis, RUR, Le Città Digitali in Italia, Roma, 2006, online version: www.censis.it

[9] Commission of the European Communities, Questions of Science - Echoes from the Science in Society Forum, Brussels, 9-11 March 2005, online version: http://ec.europa.eu/research/conferences/2005/forum2005/docs/questions_sciences_en.pdf

[10] Commission of the European Communities, Top of the web - User Satisfaction and Usage Survey of eGovernment services, Prepared by Rambøll Management, December 2004, online version: http://europa.eu.int/information_society/activities/e-Government_research/doc/top_of_the_web_report_2004.pdf

[11] Commission of the European Communities, Special Eurobarometer 224: Europeans, Science and Technology, June 2005, online version: http://ec.europa.eu/public_opinion/archives/ebs/ebs_224_report_en.pdf

[12] F. D’Ambrosi, L. Massoli, "Usabilita' e valutazione con utenti: il caso del portale ENEA", in Public@ando, Web magazine della Comunicazione Pubblica,online version: http://www.urp.it/Sezione.jsp?idSezione=917\&idSezioneRif=1050

[13] C. Delogu et al., "Un web per tutti. L'accessibilità di internet", in I Quaderni di Telema, Media2000, 2002

[14] F. Faccioli, Comunicazione Pubblica e Cultura del Servizio, Modelli, attori, percorsi, Carocci, Roma 2000

[15] B.J. Fogg et al., "What makes Web sites credible? A report on a large quantitative study", in Proceedings of CHI'01, Human Factors in Computing Systems, 61-68, Seattle, April 2001, online version: http://captology.stanford.edu/pdf/p61-fogg.pdf

[16] B.J. Fogg et al., "How do users evaluate the credibility of Web sites? A study with over 2,500 participants", in Proceedings of DUX2003, Designing for User Experiences Conference, San Francisco, CA, 5-7 June 2003 
[17] L. Massoli, "Comunicazione scientifica in rete: I modelli e le strategie di presentazione e comunicazione degli enti di ricerca italiani analizzati attraverso i loro siti web", in EAI Energia Ambiente e Innovazione, 4/2004, ENEA, 2004

[18] National Science Board, Science and Engineering Indicators 2004, Arlington, National Science Foundation, online version: http://www.nsf.gov/statistics/seind04/pdfstart.htm

[19] NIST, Communicating the future: Best Practices Conference Summary, March 2002, Gaithersburg, USA, online version: http://www.nist.gov/public_affairs/bestpractices/conf_summary.htm

[20] OECD, Engaging Citizens online for Better Policy-making, Policy Brief, Paris, 2003

[21] UK Cabinet Office, eAccessibility of public sector services in the European Union, London, November 2005. Online version:

http://www.cabinetoffice.gov.uk/e-government/resources/eaccessibility/index.asp

\section{Author}

Laura Massoli, $\mathrm{PhD}$ in Communication Sciences, works at the Italian Communications Regulatory Authority (Agcom). She has been employed at ENEA - Italian National Agency for New technologies, Energy and the Environment and has collaborated with various Italian institutions (Sociology and Communication Department- Univeristy of Roma "La Sapienza", Public Service Department, CNR, Ministry for the Economy and Finance) and European ones (European Schoolnet), taking part in projects and research activities on public communication and new technologies. She has published various articles about communication and new technologies and the related issues.

E-mail: laura.massoli@libero.it 